\title{
Acute Fetomaternal Hemorrhage Confirmed by Maternal Alfa-Fetoprotein in Monochorionic Diamniotic Neonates under $1,500 \mathrm{~g}$
}

Chaeri Yoo, $\mathrm{MD}^{1}$, Sol Han, $\mathrm{MD}^{2}$, Hyemi Jeong, $\mathrm{MD}^{1}$, Ju Sun Heo, $\mathrm{MD}^{3}$, Hyun-Seung Lee, MD, $\mathrm{PhD}^{2}$, and Jihyun Jeon, $\mathrm{MD}, \mathrm{PhD}^{2}$

${ }^{1}$ Department of Pediatrics, CHA Bundang Medical Center, CHA University School of Medicine, Seongnam, Korea

${ }^{2}$ Department of Pediatrics, CHA Gangnam Medical Center, CHA University School of Medicine, Seoul, Korea

${ }^{3}$ Department of Pediatrics, Korea University Anam Hospital, Seoul, Korea

\section{ABSTRACT}

Fetomaternal hemorrhage (FMH) is due to the entry of fetal blood into the maternal circulation. Although very rare, FMH complicates pregnancies, presents with severe symptoms, and leads to fetal death. Majority of FMH cases are idiopathic and difficult to diagnose. The known used diagnostic tests are Kleihauer-Betke Test (KBT) and flow cytometry, which can detect fetal hemoglobin in the maternal blood. However, such methods have limited use because of low sensitivity, labor-intensive and errorsusceptible procedures, poor reproducibility, and tendency to overestimate the FMH volume. Other tests include high performance liquid chromatography (HPLC) and alpha-fetoprotein (AFP) tests, which can be as favorable to confirm FMH as KBT. However, in case of acute FMH, the diagnostic results of KBT, flow cytometry, and HPLC may be false negative. AFP test is a noninvasive, fast, easily assessable, adjuvant, and confirmatory diagnostic test. Published Korean articles show confirmed FMH by KBT or HPLC in singleton late-preterm and term neonates. Herein, we report a case of monochorionic diamniotic twin neonates (birth weight $<1,500 \mathrm{~g}$ ) who presented borderline fetal hemoglobin level because of acute FMH and were diagnosed with FMH by maternal AFP. Our experience of diagnosing FMH rapidly by AFP test will be very helpful to clinicians for the prevention and treatment of FMH during pregnancy.

Key Words: Fetomaternal transfusion; Infant, very low birth weight; Monochorionic diamniotic twin; Alpha-fetoproteins

\section{INTRODUCTION}

Fetomaternal hemorrhage (FMH) is defined as the transfer of fetal blood into the maternal circulation $^{1)}$. A small amount of FMH occurs in approximately $75 \%$ of all pregnancies ${ }^{2}$ and
Received: 10 June 2020

Revised: 24 July 2020

Accepted: 29 July 2020

Correspondence to: Jihyun Jeon, MD. $\mathrm{PhD}$.

Department of Pediatrics, CHA Gang nam Medical Center, CHA University School of Medicine, 566 Nonhyeon-ro, Gangnam-gu, Seoul 06135, Korea

Tel: +82-2-3468-3000

Fax: +82-2-558-1119

E-mail: goddaugh@chamc.co.kr

Copyright(c)

By Korean Society of Neonatology. All right reserved.

This is an Open-Access article distributed under the terms of the Creative Commons At tribution Non-Commercial License (http:// creativecommons.org/licenses/by-nc/4.0), which permits unrestricted non-commercial use, distribution, and reproduction in any medium, provided the original work is pro perly cited. 
does not pose a problem to the fetus. Although massive FMH over $150 \mathrm{~mL}$ or loss of half of the fetal blood volume ${ }^{3)}$ rarely occurs, which accounts for $0.2 \%$ to $0.9 \%$ of births ${ }^{1)}$, it can be fatal and lead to fetal death or severe anemia in up to $0.04 \%$ of cases ${ }^{3)}$. Most FMH cases are idiopathic and shown onspecific symptoms, making it difficult to detect. Thus, rapid detection of FMH saves many newborns from serious injury through timely manage ment, such as emergent transfusion ${ }^{4)}$.

The Kleihauer-Betke Test (KBT) has been used to diagnose FMH. However, it may not be practical due to a combination of variability of fetal hemoglobin $(\mathrm{HbF})$ level in certain groups, tech nique sensitivity, and subjective interpretation. A case study in 2018 suggested that if there is strong clinical suspicion of FMH but the KBT is negative, the clinicians should measure the alphafetoprotein (AFP) in maternal blood to confirm $\mathrm{FMH}^{5}$. To our knowledge, there were extremely few reports of monochorionic diamniotic twin pregnancy of very low birth weight neonates (birth weight $<1,500$ g) complicated by FMH. Herein, we present our experience of FMH diagnosed by maternal AFP and rapid treatment of the twins.

\section{CASEREPORT}

A 33-year-old G0P0 woman with monochorionic diamniotic twin pregnancy at 29 gestational weeks came to our hospital due to decreased fetal movement with an absence of history of trauma. Her blood type was A+, and antibody screen test (Ab screen) was negative. Preoperative laboratory findings were as follows: hemoglobin, $11.7 \mathrm{~g} / \mathrm{dL}$; hematocrit, $35.1 \%$; prothrombin time/partial thromboplastin time, normal range; Coombs' test, negative, and others, normal range. The peak systolic velocity of the middle cerebral artery (2.8 multiples of median) showed an increase on fetal Doppler ultrasonography; it was normal 6 days back. This was suggestive of severe fetal anemia. In addition, the first baby presented with cardiomegaly and pleural/ pericardial effusion, and repeated fetal decelerations recorded in cardiotocographs, prompting emergent cesarean section.

The female twins were born at $29^{+1}$ weeks of gestational age. At birth, both looked severely pale and edematous, and neither cried nor showed any response to bag and mask ventilation. They were immediately intubated, and their heart rates recovered over 100 beats per minute after resuscitation. The first infant weighed $1,410 \mathrm{~g}$ (75th to 90th percentile) at birth, and Apgar scores at 1, 5, and 10 minutes were 1,1 , and 3 , respectively. The second infant weighed 1,420 g (75th to 90th percentile) at birth, and Apgar scores were 1,1 , and 1 , respectively. There was no evidence of placental abruption. We also suspected hydrops fetalis due to the presenting edematous skin and small amount of fluids in the abdominal ultrasonogram.

Laboratory results revealed severe anemia just as expected, metabolic acidosis, disseminated intravascular coagulation(DIC), and hypoalbuminemia (Table 1). Results related to congenital viral infection such as toxoplasmosis, rubella, cytomegalovirus, herpes, adenovirus antigen, and parvovirus B19 polymerase chain reaction and blood culture were all negative. Coombs test was also negative. They had seizures a few hours later, and electroencephalography revealed findings corresponding to diffuse cerebral dysfunctions. Brain ultrasonography showed intraventricular hemorrhage (IVH) grade IV in the first infant (Figure 1A) and grade III/IV with ischemic injury in the second infant (Figure 1B).

After excluding $\mathrm{ABO}$ incompatibility, sepsis, congenital viral infection, and DIC, we suspected FMH. HbF in maternal blood was $1.9 \%$, which was a borderline level, by high performance

Table 1. Laboratory Data of Monochorionic Diamniotic Twin Neonates

\begin{tabular}{|c|c|c|}
\hline Variable & Infant 1 & Infant 2 \\
\hline Blood type & $\mathrm{B}+$ & $\mathrm{B}+$ \\
\hline Direct Coombs' test & Negative & Negative \\
\hline Indirect Coombs' test & Negative & Negative \\
\hline $\mathrm{WBC}(/ \mu \mathrm{L})$ & 2,660 & 2,080 \\
\hline Hemoglobin (g/dL) & 2.2 & 2.4 \\
\hline Hematocrit (\%) & 7.2 & 8.3 \\
\hline Platelet $(/ \mu \mathrm{L})$ & 30,000 & 21,000 \\
\hline $\mathrm{nRBC}(\mathrm{n} / 100 \mathrm{WB})$ & 150 & 160 \\
\hline Reticulocyte (\%) & 2.49 & 3.7 \\
\hline $\mathrm{pH}$ (vein) & 7.198 & 6.911 \\
\hline Base excess (mmol/L) & -7 & -23 \\
\hline $\operatorname{Albumin}(\mathrm{g} / \mathrm{dL})$ & 1.9 & 1.8 \\
\hline $\mathrm{PT}(\mathrm{sec})$ & 17.4 & 19.8 \\
\hline aPTT (sec) & $>180$ & 48.3 \\
\hline Antithrombin III (\%) & 20 & 25 \\
\hline D-dimer (ng/mL) & $2,376.13$ & $>10,000.00$ \\
\hline Fibrinogen (mg/dL) & 83 & 94 \\
\hline $\mathrm{FDP}(\mu \mathrm{g} / \mathrm{mL})$ & 14.4 & 77.4 \\
\hline
\end{tabular}

Abbreviations: WBC, white blood cell; nRBC, nucleated red blood cell; PT, prothrombin time; aPTT, activated partial thromboplastin time; FDP, fibrinogen degradation product. 
liquid chromatography (HPLC). This value was initially considered meaningless because it was within the upper normal range. However, in case of acute hemorrhage, $\mathrm{HbF}$ may not in crease significantly. In addition, considering that $1.9 \%$ of blood loss was approximately $100 \mathrm{~mL}$, which was over $20 \mathrm{~mL} / \mathrm{kg}$ in our newborn patients, maternal $\mathrm{HbF}$ of $1.9 \%$ could be considered a significant amount. Following our review of several references about other confirmatory tests of FMH, maternal blood AFP was obtained as in previous reports of $\mathrm{FMH}^{5}$. The maternal AFP level drawn 6 days after delivery was 6,983.2 ng/mL, which was a very high level. Therefore, we diagnosed and treated FMH quickly. We transfused red blood cells, fresh frozen plasma, platelet, albumin, diuretics, and inotropics with high settings of ventilator care as acute management. Meanwhile, levels of hemoglobin and platelet gradually increased up to $13.8 \mathrm{~g} / \mathrm{dL}$ and 173,000 respectively in the first baby on the 6th day after birth. Although follow-up laboratory results associated with DIC could not be drawn considering the amount of blood volume, the absence of bleeding tendency was enough for us to judge to be out of DIC. However, her IVH progressed to hydrocephalus, which could not be improved by regular lumbar puncture. Finally, she was transferred to the department of neurosurgery for ventriculoperitoneal shunt. The patient is currently 24 months old and has undergone rehabilitation therapy under the diagnosis of spastic cerebral palsy. Developmental screening test will be scheduled after several months. The second infant expired within 72 hours after birth due to progressive multiple organ failure, although her levels of hemoglobin and platelet were finally observed nearly normal.

\section{DISCUSSION}

FMH occurs in approximately $75 \%$ of most healthy pregnant women. However, massive FMH is fatal to newborns such as in our case. Their symptoms and signs were concordant with those of acute massive FMH described by Thomas et al. ${ }^{6}$. Especially, the twin swere monochorionic diamniotic and weighed $<1,500$ g. Thus, prompt diagnosis was very important to prevent complications and provide treatment.

The KBT is the most known method for the assessment of $\mathrm{FMH}$ based on the fact that $\mathrm{HbF}$ is resistant to acid elution in contrast to adult hemoglobin ${ }^{7)}$. The counterstain is only taken up by HbF-containing cells (predominantly fetal red cells); adult hemoglobin-containing cells (adult red cells) appear as "ghost" cells ${ }^{8)}$. It is the most widely used test for quantification of the
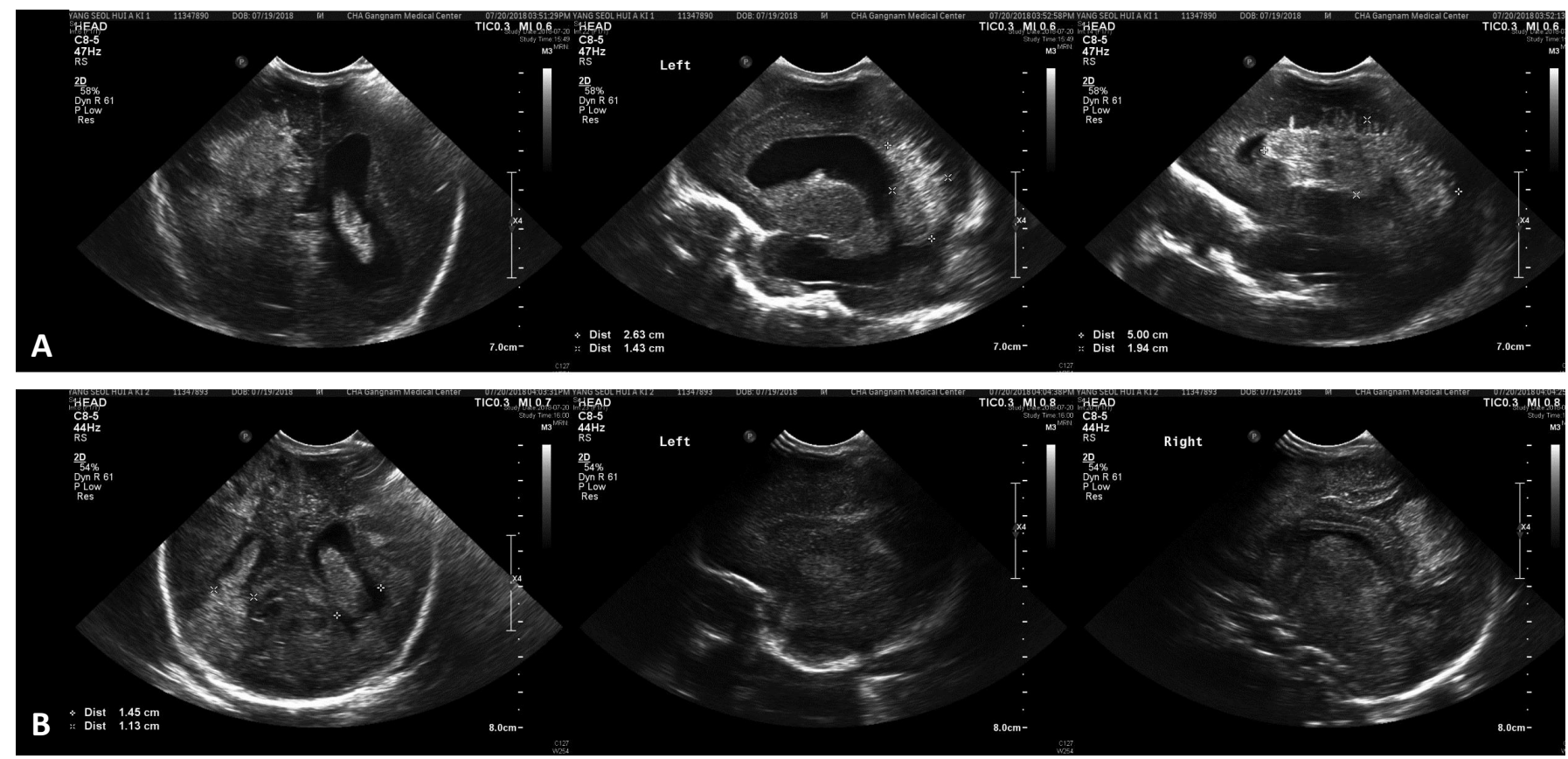

Figure 1. (A) Brain ultrasonography of the first infant. The left, middle, and right images are shown in the coronal, left sagittal, and right sagittal views, respectively. These images show intracranial hemorrhage grade IV. (B) Brain ultrasonography of the second infant. The left, middle, and right images are shown in the coronal, left sagittal, and right sagittal views, respectively. These show intracranial hemorrhage grade III/IV, R/O brain ischemic injury, and R/O brain edema. 
FMH volume, inexpensive, and availability around the clock ${ }^{9)}$. However, KBT is laborious to perform and has several significant disadvantages making a wide variation in results ${ }^{10)}$. One of the factors causing this variation is technique sensitivity as the hemoglobin elution step is sensitive to $\mathrm{pH}$, time, and temperature 10). Subjective interpretation of the stained blood film and the experience of the scientist/technician performing the test also can affect the results ${ }^{10)}$. Based on the assumption of fetal and maternal blood volume, adjustment for maternal and fetal weight and mean corpuscular volume are mandatory ${ }^{9,11)}$. It may be also falsely elevated in inherited hemoglobinopathies ${ }^{9}$. For these reasons, it often leads to over-/underestimation of the extent of $\mathrm{FMH}^{7)}$, consequently, our hospital was not able to perform KBT. Other tests were flow cytometry, HPLC, and maternal AFP. In case reports from Korea, Choi et al. ${ }^{12)}$ and Kim et al. ${ }^{13)}$ diagnosed FMH by KBT in 1999 and 2001, and Lee et al. ${ }^{14)}$ and Park et al. ${ }^{15)}$ confirmed FMH by HPLC.

The maternal $\mathrm{HbF}$ in our case was $1.9 \%$, which was a borderline level of acute blood loss to maternal circulation during only 6 days. Therefore, the tests for $\mathrm{HbF}$ were not appropriate for acute $\mathrm{FMH}$. Moreover, $1 \%$ of $\mathrm{HbF}$ detected in maternal blood corresponds to approximately $50 \mathrm{~mL}$ loss of fetal blood volume ${ }^{15)}$, and the twin neonates' blood transferred to maternal circulation could have been roughly $100 \mathrm{~mL}$. The standard assessment of the FMH severity is based on the percentage of fetal blood loss. An FMH of $20 \mathrm{~mL} / \mathrm{kg}$, which is $20 \%$ of the fetoplacental blood volume, is considered massive FMH because it is associated with significant perinatal morbidity and mortality ${ }^{16)}$. In the present case, the estimated blood loss was $30 \mathrm{~mL}$ in each infant. The estimated total blood volume from the maternal $\mathrm{HbF}$ was 100 $\mathrm{mL}$, and this volume was over $20 \mathrm{~mL} / \mathrm{kg}$ in our case.

Den Besten et al. ${ }^{5)}$ reported FMH in a premature infant con firmed by maternal AFP $(13,915 \mathrm{ng} / \mathrm{mL})$ with a negative KBT result. AFP is mainly produced and excreted by the fetal liver and fetal kidneys, respectively, in the amniotic fluid ${ }^{5,17}$. In the fetus, AFP reaches maximum levels at approximately 32 weeks of gestation, with concentrations as high as $3 \times 10^{6} \mathrm{ng} / \mathrm{mL}$, after which it decreases to $50 \mathrm{ng} / \mathrm{mL}$ at birth ${ }^{5,17)}$. During pregnancy, maternal AFP concentrations are approximately 35 and 200 ng/ $\mathrm{mL}$ in the first and third trimesters, respectively ${ }^{5)}$. Although there is no value of maternal AFP yet to use as a diagnostic standard, in the presented case, the AFP level was $6,983.2 \mathrm{ng} / \mathrm{mL}$ on the 6 th day after birth, which was a lot over $200 \mathrm{ng} / \mathrm{mL}$ and meaningful. Likewise, maternal AFP has been used as a supportive marker so far, but it has certain advantages over KBT, flow cytometry, and HPLC. Its less invasive nature enables the identification of newborns at risk for congenital anemia; thus, rapid interventions can be implemented to reduce significant morbidity and mor tality resulting from severe $\mathrm{FMH}^{18)}$. Moreover, it is easy to compare different levels obtained over the course of the pregnancy ${ }^{18)}$, and results are obtained quickly in many facilities. Therefore, maternal AFP is considered a valuable diagnostic tool.

This case is different from existing FMH cases in two aspects. Only two reports have been identified ${ }^{19,20)}$ as known; hence, FMH occurrence in very low birth weight monochorionic diamniotic twin pregnancy is quite rare and may be the first case in Korea. Second, in case of acute blood loss to the maternal circulation, the diagnosis of FMH could be confirmed by maternal AFP. In fetuses whose mother's AFP level was checked before delivery, impending death and severe complications associated with $\mathrm{FMH}$ can be prevented. Therefore, testing AFP in pregnant women with strong clinical suspicion of FMH can be a good alternative for detecting FMH.

\section{ARTICLE INFORMATION}

\section{Ethical statement}

This case report was approved by the Institutional Review Board of Gangnam CHA Medical Center, CHA University (No. GCI-18-32), after agreement of the infants' parents.

\section{Conflicts of interest}

No potential conflict of interest relevant to this article was reported.

\section{Author contributions}

Conception or design: C.Y., S.H., H.J., J.S.H., H.S.L., J.J. Acquisition, analysis, or interpretation of data: C.Y., S.H., H.J. Drafting the work or revising: C.Y., J.J.

Final approval of the manuscript: J.J.

\section{ORCID}

Chaeri Yoo https://orcid.org/0000-0003-0299-7775

Jihyun Jeon https://orcid.org/0000-0002-4512-2728

\section{Acknowledgments}

None 


\section{REFERENCES}

1. Menendez Hernando C, Chacon Aguilar R, Farinas Salto M, Perez Crespo R, Martin Molina R, Moreno Novillo R, et al. Severe neonatal anemia due to fetomaternal hemorrhage: an ilustrative case. Arch Argent Pediatr 2019;117:e142-6.

2. Solomonia N, Playforth K, Reynolds EW. Fetal-maternal he morrhage: a case and literature review. AJP Rep 2012;2:7-14.

3. Ahmed M, Abdullatif M. Fetomaternal transfusion as a cause of severe fetal anemia causing early neonatal death: a case report. Oman Med J 2011;26:444-6.

4. Weisberg L, Kingdom J, Keating S, Ryan G, Seaward G, Kelly E, et al. Treatment options in fetomaternal hemorrhage: four case studies. J Obstet Gynaecol Can 2004;26:893-8.

5. Den Besten G, van der Weide K, Schuerman FA, Michael Cotten $\mathrm{C}$, Rondeel JM. Establishing the cause of anemia in a premature newborn infant. Lab Med 2018;49:e74-7.

6. Thomas A, Mathew M, Unciano Moral E, Vaclavinkova V. Acute massive fetomaternal hemorrhage: case reports and review of the literature. Acta Obstet Gynecol Scand 2003;82:479-80.

7. Doshi K, Shastry S, Shivhare A, Raturi M. Cellular mimicry in Kleihauer-Betke assay. Glob J Transfus Med 2016;1:85-7.

8. Duguid JK, Bromilow IM. Laboratory measurement of fetomaternal hemorrhage and its clinical relevance. Transfus Med Rev 1999;13:43-8.

9. Stefanovic V. Fetomaternal hemorrhage complicated preg. nancy: risks, identification, and management. Curr Opin Obstet Gynecol 2016;28:86-94.
10. Scientific subcommittee of the Australian \& New Zealand Society of Blood Transfusion Inc. Guidelines for laboratory assessment of fetomaternal haemorrhage. Sydney: The Society, 2002:1-14.

11. Kim YA, Makar RS. Detection of fetomaternal hemorrhage. Am J Hematol 2012;87:417-23.

12. Choi JW, Oh JH, Seok JE, Lee YJ, Oh YK. A case of matemal hemorrhage. J Korean Soc Neonatol 1999;6:272-5.

13. Kim HK, Choi MY, Yoon HS, Yun BY, Bae SW, Son DW. Clinical study on massive fetomaternal hemorrhage. Korean J Perinatol 2001;12:267-73.

14. Lee CH, Kim JK, Han MK, Kim JW, Lee JJ. Two cases of massive fetomaternal hemorrhage treated by exchange transfusion. Korean J Perinatol 2008;19:203-8.

15. Park HC, Park SK, Choi MS. Neonatal severe anemia due to massive fetomaternal hemorrhage. Perinatology 2019;30:40-5.

16. Giacoia GP. Severe fetomaternal hemorrhage: a review. Obstet Gynecol Surv 1997;52:372-80.

17. Maier JT, Schalinski E, Schneider W, Gottschalk U, Hellmeyer L. Fetomaternal hemorrhage (FMH), an update: review of literature and an illustrative case. Arch Gynecol Obstet 2015;292:595602.

18. Stroustrup A, Plafkin C. A pilot prospective study of fetomaternal hemorrhage identified by anemia in asymptomatic neonates. J Perinatol 2016;36:366-9.

19. Verco CJ, Jones WR. Monoamniotic twin pregnancy compli cated by massive fetal-maternal haemorrhage. Aust N Z J Obstet Gynaecol 1981;21:186-7.

20. Watanabe N, Jwa SC, Ozawa N, Sago H. Sinusoidal heart rate patterns as a manifestation of massive fetomaternal hemorrh age in a monochorionic-diamniotic twin pregnancy: a case report. Fetal Diagn Ther 2010;27:168-70. 